\title{
The Politics of Blockchain
}

\author{
Robert Herian ${ }^{1}$
}

Published online: 12 May 2018

(C) Springer Science+Business Media B.V., part of Springer Nature 2018

\section{Introduction}

Melanie Swan (2015) defines blockchain as follows:

The blockchain is like another application layer to run on the existing stack of Internet protocols, adding an entire new tier to the Internet to enable economic transactions, both immediate digital currency payments (in a universally usable cryptocurrency) and longer-term, more complicated financial contracts. A blockchain is quite literally like a giant spreadsheet for registering all assets, and an accounting system for transacting them on a global scale that can include all forms of assets held by all parties worldwide. Thus, the blockchain can be used for any form of asset registry, inventory, and exchange, including every area of finance, economics, and money; hard assets (physical property); and intangible assets (votes, ideas, reputation, intention, health data, etc.). (Swan 2015, pp. x-xi)

Swan is without a doubt an acolyte or evangelist of blockchain technologies; she is, to put it another way, a stakeholder in the techno-social futurity of blockchain. Of particular note in Swan's definition are ways in which a collapsing of the human into the economic is envisaged, and the necessary role blockchain will have in achieving this end. But whilst Swan's definition offers broad technical details, it is rather more interesting as a symptom of the sustained insistence of neoliberal economic reason at work shaping the 'blockchain ecosystem'. This 'ecosystem' is thus a community of thought and practice centred on a specific technology or set of technologies called 'blockchain', but one motivated by universal adherence to innovationism and above

Robert Herian

robert.herian@open.ac.uk

1 The Faculty of Business and Law, The Open University Law School, The Open University, Milton Keynes MK7 6AA, UK 
all the desires of what Morozov (2014) calls solutionists. As such Swan, albeit inadvertently, reveals the political at stake in the present blockchain moment.

A number of reports, commentary and academic studies during the last three years have revealed and demonstrated a growing trend in blockchain infrastructure applications extending from an original position with cryptocurrencies (e.g. Bitcoin) to many different social, cultural, economic and political arenas (The Economist 2015; Swan 2015; Golumbia 2016; Moody's 2016; Tapscott and Tapscott 2016; Adams et al. 2017; Aste et al. 2017). Underpinning this trend is the growth of a 'blockchain ecosystem' via an ethics of neoliberal political economy which is driving forward numerous post-cryptocurrency concepts and use-cases rooted in, for example: reimagining and strengthening the legitimacy and transparency of big data; solving issues of trust online by fostering new post-trust worlds; creating harmony between individuals as consumer/citizens by rendering the line between business and government (commerce and State) porous, as Swan's definition above showed; and decentralising and disrupting 'old' or legacy networks and institutions of power in order to regenerate them. ${ }^{1}$

The aim of this supplement is to explore and critique this 'blockchain ecosystem', the politics it tries to hide, and the legal and regulatory ramifications it inaugurates. The following essays do not portray blockchain as providing all, if any, of the answers to the world's problems. Instead, the challenge is in part to understand the tensions faced by law and regulation in defining blockchain within the ongoing networking, digitalisation, and datafication of the social. Success in this regard will be measured in the coming months and years by the grip that regulatory authorities and governments are able to maintain on the various strands of blockchain research, development, application, implementation, and conduct - a grip, moreover, that is able to be maintained alongside the regulatory conundrums that continue to plague the wider field of network technologies which are themselves still evolving, mutating, impacting, but not necessarily benefiting community or public interest ahead of private, commercial power. Understanding the extent to which law and regulation will play a role in securing democratic accountability of these powerful and far-reaching technologies is or ought to be a key concern for blockchain scholars and practitioners of all stripes.

The essays here come from Australia, United States, United Kingdom and Sweden, and thus offer a network of critical thought that echoes the distributed reach of the technology in question. The authors all draw from domestic legal experience and expertise and bring to light problems faced by governments and regulatory authorities in understanding blockchain. The aim is to contribute much-needed critical analyses and interventions into the growing field of transnational, transdisciplinary blockchain scholarship and debate. The concern here is not to disparage or vilify blockchain technologies nor those invested in them in terms of their time, energy and capital, but to provide, at the very least, a critical vocabulary with which to understand and evaluate the impacts of the technology.

\footnotetext{
${ }^{1}$ See for example the manifesto of the think-tank, Blockchain for Good 2017.
} 
To that end the themes of law, governance and regulation covered by this supplement mirror interests and concerns in wider blockchain discourse, and the following essays are not aimed at abstract theorising of the blockchain ecosystem so much as deliberate engagement with the paradoxical matrix of promises, benefits, threats and harms that the technology and its stakeholders engender. Of particular interest here are questions of: control, including blockchain as 'a type of control technology that displaces or even replaces law' (Käll); property, specifically jurisdiction and contract, including the potential of so-called 'smart contracts' run on blockchain to facilitate 'computational forms of legal conduct' (Goldenfein and Leiter); sovereignty, including the tendency of technologists to use sovereignty as a synonym for autonomy (Manski and Manski); governance, and regulation, including the problem of understanding what regulating blockchain means amid the bluster and chaos of its present moment (Herian). Confronting the ideological parameters in which blockchain exists, and the commercial and individual interests and concerns that the technology channels and structures are vital in order to cut through the problematic of blockchain hype and challenge hollow sentiments of entrepreneurial 'disruption'. The critique demonstrated by this supplement is thus directed, in part, at the problematic of hype in order to analyse and better understand this moment of blockchain's ascendancy.

\section{References}

Adams, Richard., Glenn Parry, Phil Godsiff, and Peter Ward. 2017. The future of money and further applications of blockchain. Strategic Change 26 (5): 417-422.

Aste, Tomaso, Paolo Tasca, and Tiziana Di Matteo. 2017. Blockchain technologies: The foreseeable impact on society and industry. Computer 50 (9): 18-28.

Blockchain for good. https://www.blockchainforgood.com/manifesto-1/. Accessed 3 August 2017.

Golumbia, David. 2016. The politics of Bitcoin: Software as right-wing extremism. Minneapolis: University of Minnesota Press.

Moody's Investor Report. (2016). Blockchain can bring benefits to the financial industry and beyond, given time, July. https://www.moodys.com/research/Moodys-Blockchain-can-bring-benefits-to-thefinancial-industry-and-PR_352414. Accessed 3 August 2017.

Morozov, Evgeny. 2014. To save everything, click here: Technology, solutionism and the urge to fix problems that don't exist. London: Penguin.

Swan, Melanie. 2015. Blockchain: Blueprint for a new economy. Sebastopol: O'Reilly.

Tapscott, Don., and Alex Tapscott. 2016. Blockchain revolution: How the technology behind Bitcoin is changing money, business and the world. London: Portfolio Penguin.

The Economist. 2015. The trust machine, 31 October-6 November. 